\title{
MKI67 Positive
}

National Cancer Institute

\section{Source}

National Cancer Institute. MKI67 Positive. NCI Thesaurus. Code C146686.

An indication that MKI67 expression has been detected in a sample. 